University of Nebraska - Lincoln

DigitalCommons@University of Nebraska - Lincoln

Civil and Environmental Engineering Faculty

Publications

8-8-2017

Effects of source and seasonal variations of natural organic matters on the fate and transport of $\mathrm{CeO} 2$ nanoparticles in the environment

Zhen Li

Endalkachew Sahle-Demessie

George A. Sorial

Changseok Han

Follow this and additional works at: https://digitalcommons.unl.edu/civilengfacpub

This Article is brought to you for free and open access by the Civil and Environmental Engineering at DigitalCommons@University of Nebraska - Lincoln. It has been accepted for inclusion in Civil and Environmental Engineering Faculty Publications by an authorized administrator of DigitalCommons@University of Nebraska Lincoln. 


\title{
Effects of source and seasonal variations of natural organic matters on the fate and transport of $\mathrm{CeO}_{2}$ nanoparticles in the environment
}

\author{
Zhen Li ${ }^{\text {a }}$, Endalkachew Sahle-Demessie ${ }^{\text {b,* }}$, Ashraf Aly Hassan ${ }^{\text {c }}$, Jonathan G. Pressman ${ }^{\text {b }}$, \\ George A. Sorial ${ }^{\mathrm{a}}$, Changseok Han ${ }^{\mathrm{b}}$

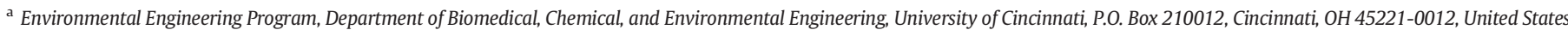 \\ b U.S. Environmental Protection Agency, Office of Research and Development, NRMRL, 26 W. Martin Luther King Drive (MS 443), Cincinnati, OH 45268, United States \\ c Department of Civil Engineering, University of Nebraska Lincoln, P.O. Box 886105, Lincoln, NE 68588-6105, United States
}

\section{H I G H L I G H T S}

- Molecular structure and macrocomposition of Ohio river NOMs differs from SRHA.

- Fate and transport of $\mathrm{CeO}_{2}$-NPs influenced by seasonal variation of Ohio river-NOMs

- Summer OR-NOM showed higher stabilization effect on the $\mathrm{CeO}_{2}$ than the winter NOM.

- Modified DLVO theory for steric repulsive energy indicated greater energy barrier.
G R A P H I C A L A B S T R A C T

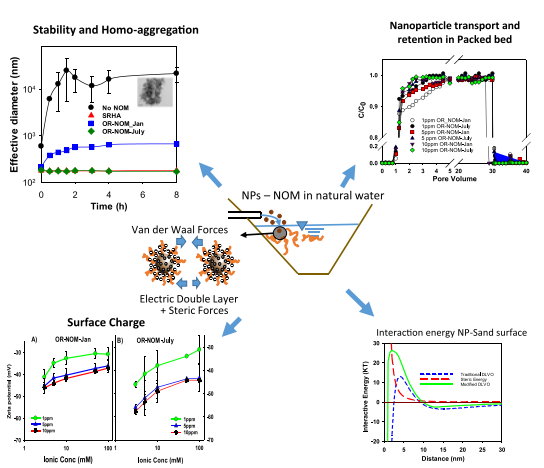

\begin{abstract}
A B S T R A C T
Natural organic matter (NOM) affects the stability and transport of nanoparticles (NPs) in natural waters by modifying their physiochemical properties. Source location, and seasonal variations, influence their molecular, physical and electrical charge properties. To understand the variations of NOM on the mobilization of NPs, large volumes of water were collected from the Ohio River (OR) over winter and summer seasons and dissolved NOMs were concentrated. The chemical and structural differences of these NOMs were compared with the Suwannee River humic acid (SRHA) SRHA using ${ }^{1} \mathrm{H}$ and ${ }^{13} \mathrm{C}$ nuclear magnetic resonance spectroscopy, and Fourier transforms infrared (FTIR) spectroscopy. Thermal analysis and FTIR confirmed that differences in composition, structure, and functional groups are a result of SRHA fractionation compared to whole molecule OR-NOM. The influence of OR-NOMs on the surface charge of $\mathrm{CeO}_{2} \mathrm{NPs}$ and the effects on the transport and retention in a three-phase (deposition-rinse-re-entrainment) sand-packed columns were investigated at $\mathrm{CeO}_{2} \mathrm{NPs}$ initial concertation of $10 \mathrm{ppm}$, pH 6.8, increasing ionic strength $(3,5$, and $10 \mathrm{mM})$, retention time of $1 \mathrm{~min}$, and increasing NOM concentration $(1,5$, and $10 \mathrm{ppm})$. The summer OR-NOM showed higher stabilization and mobilization effect on the $\mathrm{CeO}_{2}$ than the winter NOM; while their effect was very different form the SRHA. The stabilization of NPs is attributed to both electrostatic and steric effects. The differences in the chemical structure of the complex and heterogeneous NOMs showed disparate reactivity and direct impact on $\mathrm{CeO}_{2}$-NPs stability. Using SRHA to study the effect of NOM for drinking water related assessment does not sufficiently represent the natural conditions of the environment.
\end{abstract}

Published by Elsevier B.V.

\footnotetext{
* Corresponding author.

E-mail address: sahle-demessie.endalkachew@epa.gov (E. Sahle-Demessie).
} 


\section{Introduction}

The number of consumer products containing nanoparticles (NPs) and nanotubes is on the rise. The understanding of the ultimate fate of these products across their life cycle and the potential consequences to human and ecological health is incomplete (Lecoanet and Wiesner, 2004; Bettini et al., 2017). Some NPs have been shown to pose significant chronic toxicity for algae (Zeyons et al., 2009; Johnston et al., 2010) and zebrafish (Asharani et al., 2011). Inhaled NPs could be absorbed by human lung fibroblast cells at low concentrations (100 $\mu \mathrm{g} / \mathrm{l}$ ) (Limbach et al., 2005) and cause oxidative stress of human lung cells indicating lipid peroxidation and cell membrane damage (Lin et al., 2006). Cerium oxide NPs ( $\left.\mathrm{CeO}_{2} \mathrm{NPs}\right)$ are used as a fuel additive, for UV blocking and ceramic polishing (Goharshadi et al., 2011; Masui et al., 2000; Montini et al., 2016), catalysis (Jeong and Kim, 2009), and fuel cells (Yu and Xi, 2012).

Natural organic matter (NOM) exists ubiquitously in the environment and is known to modify the physiochemical properties and morphologies of colloids. NOM can mobilize and facilitate the transport of NPs, increasing their hazard potential. Adsorption of NOM to NPs surfaces increase electrostatic repulsion (Akbour et al., 2002; Brown and Jaffé, 2001; Deshiikan et al., 1998; Lin et al., 2010; Pelley and Tufenkji, 2008; Tian et al., 2010). The effects of water chemistry on the stability and mobility of NPs have been observed to follow the DerjaguinLandau-Verwey-Overbeek theory (DLVO theory), which accounts for electrostatic repulsion and van der Waals attraction (Lin et al., 2010; Li et al., 2011). However, in the presence of NOM or other stabilizing agents, non-DLVO forces such as hydrogen bonding, hydration pressure, and steric forces also play important roles but are not as well understood (Zhang et al., 2009).

NOMs vary with the source location, seasonal change, and extraction or isolation processes (Sharp et al., 2006). Even relatively subtle changes can significantly affect NOM's morphology, hydrophobicity and electrical charge. Many researchers have used commercially available fractionated NOM isolates such as Suwannee River humic acid (SRHA). The fractionated SRHA, though standardized, does not provide a good representation of surface water relevant NOM. Therefore, it is necessary to assess the impacts of the NOMs that were isolated from the source and validated for the characteristics of drinking water interest (McCurry et al., 2011; Pressman et al., 2012). NOM characterization methods used in these studies included TOC, $\mathrm{UV}_{254}$, disinfection byproducts, fluorescence spectroscopy, HPLC-size exclusion chromatography, and elemental analysis. The results of multiple studies generally demonstrated the lyophilized reconstituted NOM was similar to the source NOM and could be used as a standardized NOM source for research studies (McCurry et al., 2011; Pressman et al., 2012).

The high adsorption of NOM to metal oxides such as $\mathrm{Fe}_{2} \mathrm{O}_{3}, \mathrm{TiO}_{2}$, $\mathrm{Al}_{2} \mathrm{O}_{3}$, and $\mathrm{ZnO}$ was reported previously (Mosley et al., 2003; Yang and Xing, 2009). There are limited studies exploring the effect of water chemistry on the transport and retention of $\mathrm{CeO}_{2} \mathrm{NPs}$ (Cornelis et al., 2010) and the potential removal using drinking water filter treatment ( $\mathrm{Li}$ et al., 2013). With respect to $\mathrm{NOM}$ and $\mathrm{CeO}_{2}$ interactions, a few aggregation and settling studies have been conducted reporting that the adsorption of NOM onto $\mathrm{CeO}_{2}$ significantly reduces their aggregation and stabilizes them under many conditions (Zhang et al., 2009; Quik et al., 2010; Seaton et al., 2009). Liu et al. studied the deposition of $\mathrm{CeO}_{2}$ on a collector surface in both Quartz Crystal Microbalance with dissipation monitoring and column experiments (Liu et al., 2012). Many of these studies have attributed the stability of NOM coated NPs to enhanced electrostatic and steric effects (Ghosh et al., 2008; Marzun et al., 2014; Badawy et al., 2010). While the electrostatic effects were demonstrated by an increase in the absolute value of zetapotential of $\mathrm{CeO}_{2} \mathrm{NPs}$, the enhanced steric forces were not fully demonstrated.

This investigation is part of an ongoing study that is intended to evaluate the effectiveness of current drinking water technologies on removing nanoscale particles from source water. The objective of this research is to evaluate and analyze the behavior of $\mathrm{CeO}_{2} \mathrm{NPs}$ in the presence of NOM in saturated porous media under simulated conditions of drinking water treatment. NOM was extracted concentrated and lyophilized from a local drinking water source during both winter and summer seasons. NOM extraction was conducted using validated methods to ensure the reconstituted NOM is similar to the original (Pressman et al., 2010). The chemical groups and compositions characteristics of the NOM were studied and compared with SRHA including thermal, spectroscopic, and elemental analysis. The transport of $\mathrm{CeO}_{2}$ in the presence of NOM was investigated in packed-bed columns, and the effect of NOM was compared at different concentrations, ionic strength, and seasonal change. Modified-DLVO modeling was performed to analyze the stabilizing effect of the NOM by demonstrating the steric repulsion. This work assesses the impact of NOM on the transport and fate of $\mathrm{CeO}_{2} \mathrm{NPs}$ in porous medium from the point of view of a drinking water treatment. We believe this is the novel research to provide quantitative information on the transport of $\mathrm{CeO}_{2} \mathrm{NPs}$ in the presence of NOM from a local drinking water source collected over multiple seasons.

\section{Theoretical consideration}

The transport and deposition of NPs in porous media is limited by the frequency of collision between the colloids and the matrix surface and by the collision efficiency. The classical colloid filtration theory (CFT) can be used to quantitatively compare the attachment and deposition of $\mathrm{CeO}_{2}$ NPs sand particles in the packed-bed (Yao et al., 1971). The primary assumption in developing CFT was the deposition rate can be calculated as sum of the contributions from three individual retention mechanisms: Brownian diffusion, interception, and sedimentation (Tufenkji and Elimelech, 2004). A single-collector removal efficiency $\left(\eta_{0}\right)$ combines all the three contributions to yield a ratio between the rate at which particles make contact with the collectors and the rate at which particles flow towards the collector.

$\eta_{o}=\eta_{D}+\eta_{I}+\eta_{G}$

where the subscripts $D, I$ and $G$ stand for Brownian diffusion, interception and sedimentation components (Elimelech and O'Melia, 1990). The frequency of collision is influenced by the characteristics of NPs and the matrix, and hydrodynamics of the fluid flow and the collision efficiency is the fraction of collisions results in the attachment and sorption of the NPs on the matrix surface. The CFT is employed for the estimation of the dimensionless attachment efficiency, $K_{a t t}$, which represents the ratio of the collisions resulting in attachment to the total number of collisions between NPs and collector grains. The attachment efficiency of the bed can be expressed as a function of the relative effluent concentration $C / C_{0}$, where $C$ is the effluent concentration at time $t$, and $C_{0}$ is the influent concentration, shown in Eq. (1) (Mylon et al., 2004):

$K_{a t t}=-\frac{2 d_{c}}{3(1-\varepsilon) \eta_{0} L} \ln \left(C / C_{0}\right)$

where $d_{c}$ is the median diameter of the porous media, $\varepsilon$ is the bed porosity, and $L$ is the length of the bed. The theoretical clean bed singlecollector contact efficiency, $\eta_{0}$ that describes the particle transport to an individual collector before particle accumulation alters the collector geometry. Single collector efficiency can be calculated as the sum of individual contributions each transport mechanism, and the overall correlation equation (Tufenkji and Elimelech, 2004).

Aggregation and deposition behavior of NPs in aquatic environments are controlled by particle-to-surface interactions. These interactions have traditionally been described by the DLVO theory of colloidal stability. The classic DLVO theory of NPs stability considers interaction 
forces of van der Waals attraction and electrical double layer forces (Ryan and Elimelech, 1996). However, non-DLVO forces such as steric and hydration forces can also play an important role. The extent of steric forces have been derived for particles with adsorbed layers of polymers or surfactants that might lead to steric repulsion (Alexander, 1977; Petosa et al., 2010).

\section{Material and methods}

\subsection{Concentration, lyophilization, and reconstitution of Ohio River NOM} samples

Raw water from a full-scale drinking water treatment plant was first pumped through two 19P37-30 Membralox ceramic ultrafiltration (UF) membranes (0.02- $\mu \mathrm{m}$ pore size, Pall Corp., Port Washington, NY), which was used to remove suspended particulates and enabling the deliberate study of dissolved NOM (Pressman et al., 2010). Following UF, ion exchange resin (Ambersep 200H hydrogen-form, Rohm and Haas, Philadelphia, PA) was used to remove calcium, magnesium, and sodium ions to reduce membrane fouling and osmotic pressure. Then, three Filmtec BW30-4040 reverse osmosis (RO) membranes (in-series operation) (Dow, Midland, MI) were used for concentration $(165 \times$ by volume). The concentrate was then collected for further processing, and the permeate was discarded. Barium chloride was added to the concentrate in a multiple stage treatment process (barium-to-sulfate molar ratio of $0.9: 1$ ) to precipitate and remove sulfate, which has been shown to negatively affect the quality of freeze-dried NOM concentrates by forming sulfuric acid during lyophilization and preventing the formation of a low-moisture dried product (McCurry et al., 2011). The dissolved NOM was then lyophilized in a VirTis VirTual EL pilot scale freeze-dryer (SP Industries, Warminster, PA), following a multistep protocol with control over the shelf temperature, chamber pressure, and step length developed in previous research (McCurry et al., 2011). The solid NOM was stored in an airtight container in the dark until reconstitution. Reconstitution was performed by dissolving NOMs in DI water for desired concentrations $(1,5,10 \mathrm{mg} / \mathrm{l})$ following procedures developed in previous research. The solutions were mixed for $1 \mathrm{~h}$ to ensure a homogeneous solution. The $\mathrm{pH}$ of the NOM solution was adjusted to a near neutral $\mathrm{pH}$ of 6.8 using $\mathrm{NaOH}$ to simulate natural water. NOM produced with these procedures was validated as representative of the source NOM for the water quality parameters typically measured in drinking water systems, including total organic carbon (TOC), ultraviolet at $254 \mathrm{~nm}\left(\mathrm{UV}_{254}\right)$, and a suite of disinfection byproducts (Pressman et al., 2012; Rossman, 2014). In this study, the NOM samples were collected in January (OR-NOM-Jan) and July (OR-NOM-July) to show seasonal variations. For comparison to other literature reports, SRHA from the IHSS was selected as a standard reference.

\subsection{Characterization of NOM}

Due to the complex nature of NOMs, a variety of tests were used to characterize them fully. Thermal analysis was used for qualitative comparisons of gross chemical composition based on their pyrolysis decomposition profiles. Chemical identities of individual species including chemical functional groups of the NOM were analyzed by using Fourier Transform Infrared (FTIR) spectroscopy. The third method used include composition analysis, ${ }^{13} \mathrm{C}$ - and ${ }^{1} \mathrm{H}$, nuclear magnetic resonance (NMR) spectroscopy. These techniques provide chemical-specific information, but they required substantial sample preparation.

Thermal gravimetric analysis (TGA) was applied to evaluate the thermal stability of NOM by measuring the amount and rate of weight change of a material as a function of temperature. About $5 \mathrm{mg}$ NOM sample was weighed on an alumina crucible and kept at isothermal conditions of $30^{\circ} \mathrm{C}$ for $10 \mathrm{~min}$ under air flow $(20 \mathrm{l} / \mathrm{min})$ and then heated from 30 to $800^{\circ} \mathrm{C}$ in an air atmosphere at a rate of temperature increase of $10^{\circ} \mathrm{C} / \mathrm{min}$. Attenuated total reflection FTIR (Perkin-Elmer model 200) spectroscopy equipped with a Nicolect 752 spectrophotometer and a 45-degree ZeSe flat plate crystal was used to determine functional groups.

TOC was sampled in triplicate and measured in a non-dispersive infrared gas Shimadzu Analyzer (TOC-5000A). Samples were analyzed according to USEPA method 415.3 (Martin, 2003; Potter and Wimsatt, 2012) with a combustion catalytic TOC analyzer (model TOC-VCSH, Shimadzu Corporation, Columbia, MD). UV absorbance at a wavelength of $254 \mathrm{~nm}$ was measured according to SM5910 (Apha, 1998) with a Nicolet Evolution 300 spectrophotometer (Thermo Scientific, Waltham, MA, A UV-spectrophotometer).

Knowledge of the structures of natural organic matter (NOM) in waters is needed for determining its origin and fate, understanding its subtle interactions with pollutants, natural surfaces and engineered NPs in ecosystems (Luthy et al., 1997). All the ${ }^{1} \mathrm{H}$ and ${ }^{13} \mathrm{C}$ solid-state NMR (ssNMR) experiments were conducted at $7.04 \mathrm{~T}$ on a Varian Unity Inova spectrometer at the SCS NMR Facility of the University of Illinois at Urbana-Champaign, operating at the resonance frequency of $v_{0}$ $\left({ }^{1} \mathrm{H}\right)=300.1 \mathrm{MHz}$ and $\nu_{0}\left({ }^{13} \mathrm{C}\right)=75.4 \mathrm{MHz}$ at room temperature. $\mathrm{A}$ Varian/Chemagnetics $4 \mathrm{~mm}$ double-resonance APEX HX magic-angle spinning (MAS) probe was used for all MAS experiments under a magic-angle spinning rate of $10 \mathrm{kHz}$ and TPPM ${ }^{1} \mathrm{H}$ decoupling. The samples were packed into $4 \mathrm{~mm}$ O.D. zirconia rotors (the amount of sample varies from 16.1 to $83.3 \mathrm{mg}$ ). Experimental carbon chemical shift is referencing, pulse calibration and cross-polarization conditions were done using powdered hexamethylbenzene (HMB), which has a chemical shift of $17.3 \mathrm{ppm}$ (for the methyl peak) about the primary standard, TMS at $0 \mathrm{ppm}$. For ${ }^{1} \mathrm{H}$ direct-polarization MAS (DPMAS), with a ${ }^{1} \mathrm{H} 90^{\circ}$ pulse-length of $2.5 \mu$ s and 32 transients were acquired with a recycle delay of $5 \mathrm{~s}$. For ${ }^{13} \mathrm{C}$ cross-polarization MAS (CPMAS), the ${ }^{1} \mathrm{H} 90^{\circ}$ pulse width was $2.5 \mu$ s with a contact time of $1 \mathrm{~ms}$. A delay of $3 \mathrm{~s}$ was used, for the recycle loop with some transients ranging from 1500 to 10,000 scans were acquired. For CPMAS with interrupted ${ }^{1} \mathrm{H}$ decoupling (CPMAS/IDREF), the decoupler was turned off for $40 \mu \mathrm{s}$ before data acquisition. An extra refocusing pulse of $4.5 \mu$ s, synchronized with two rotor periods, was used to avoid a large first-order phase correction.

Inductively coupled plasma atomic emissions spectroscopy (ICPAES) analysis was performed with an iCAP ${ }^{\mathrm{TM}} 6000$ spectrometer (Thermo Scientific, Waltham, MA) following USEPA method 200.7 (Maxfield and Mindak, 1985). Ion chromatography (IC) analysis was performed according to USEPA method 300.1 (Hautman and Munch, 1997).

\subsection{Characterization of $\mathrm{CeO}_{2}$ nanoparticles}

High-grade $\mathrm{CeO}_{2}$ NPs were obtained from Alfa Aesar (Ward Hill, MA) in suspension form (18\% by wt. in water) and were used as received. Stock solutions of $\mathrm{CeO}_{2}$ nanoparticles were prepared by diluting the original suspension to obtain selected $\mathrm{CeO} 2-\mathrm{NP}$ concentrations 1,10 and $30 \mathrm{mg} / \mathrm{l}$. The electrolyte concentration, and $\mathrm{pH}$ of stock solutions were adjusted to the desired levels by adding appropriate amount of standard solutions: $\mathrm{NaCl}$ solution $(1 \mathrm{M}), \mathrm{NaOH}(1 \mathrm{M})$, and $\mathrm{HCl}(1 \mathrm{~N})$ prior to adding selected amounts of NOM. The NPs were characterized using dynamic light scattering (DLS), transmission electron microscopy (TEM), and powder X-ray diffraction as described previously (Li et al., 2011).

\subsection{Zeta potential measurements of $\mathrm{CeO}_{2}$ in the presence of OR-NOM}

Laser Doppler velocimetry in conjunction with phase analysis light scattering (Zeta-Sizer Nano, Malvern) was used to measure the $\zeta$-potential. $\mathrm{CeO}_{2}$-NPs suspensions were prepared with various initial ionic strengths of $\mathrm{NaCl}(3,10,50$ and $100 \mathrm{mM})$ and $\mathrm{NOM}$ concentrations $(0,1,5$ and $10 \mu \mathrm{g} / \mathrm{l})$. 


\subsection{Stability, transport, and deposition of $\mathrm{CeO}_{2}$ nanoparticles}

Glass columns ( $7.5 \mathrm{~cm}$ length $\times 2.54 \mathrm{~cm}$ ID) were packed with industrial mineral silica sand of $20 \times 30$ mesh size fraction (geometric mean diameter $=0.717 \mathrm{~mm}$ ) that contains $98.2 \% \mathrm{SiO}_{2}$ and a trace amount of metal oxides (AGSCO Co., IL). The treatment and packing of porous media were described previously (Li et al., 2011; Li et al., 2013). Before starting column test runs and introducing NPs suspension, the column was pre-conditioned with NOM solutions (without additional ions) for at least 10 pore volumes. At the onset of a test, the deposition phase consisted of $\mathrm{CeO}_{2} \mathrm{NP}$ suspension with $\mathrm{NaCl}(3,10,50$ and $100 \mathrm{mM})$ and NOM concentrations $(0,1,5$ and $10 \mathrm{ppm})$ introduced to the column for 30 pore volumes. The rinse phase followed in which the flow was switched back to particle-free NOM solutions with the same ionic concentration as the deposition phase. The $\mathrm{NaCl}$ and NOM concentration were kept constant during each experiment but varied for different tests. Finally, the re-entrainment phase consisted of NOM solution with no additional ions. The NP concentration was monitored at the effluent of the column using an on-line UV-visible spectrophotometer. Three replicate samples were analyzed for each set of conditions. Temporal changes in effluent concentration were presented as breakthrough curves using normalized effluent concentration versus pore volume.

\section{Results and discussion}

\subsection{Characterization of $\mathrm{CeO}_{2} \mathrm{NPS}$}

The average hydrodynamic diameter of $\mathrm{CeO}_{2} \mathrm{NPs}$ was $152.7 \mathrm{~nm}$ as determined by DLS based on laser intensity and $62 \mathrm{~nm}$ using laser diffraction analyzer (Fig. S1(A)). The crystallographic phases of $\mathrm{CeO}_{2} \mathrm{NPs}$ observed by XRD analysis is presented in Fig. S1(B) (Supplemental Section). X-ray diffraction patterns fitted well with the crystalline pattern of $\mathrm{CeO}_{2}$ phase, confirming the purity of the particles. A representative TEM image of $\mathrm{CeO}_{2} \mathrm{NPs}$ shows the variability in shape and size of the primary particles (Fig. S1(C)).

\subsection{Characterization of NOM}

The concentration, $\mathrm{UV}_{254}$ absorption, and TOC of NOM are shown in Table S1 (Supplemental Section). While the highest NOM concentration was found in OR-NOM-Jan, the TOC levels are reversed SRHA > ORNOM-July > OR-NOM-Jan. $\mathrm{UV}_{254}$ is frequently used as indicator of humic acid concentration similarly to TOC. However, both parameters did not agree qualitatively on the order. Elemental analysis with ICPAES analyses of OR-NOM are shown in Tables S2 and S3 indicating that OR-NOM-July has higher sulfate, sulfur, calcium, and magnesium than OR-NOM-Jan. On the other hand, both seasons showed similar carbon, hydrogen, nitrogen and oxygen content.

\subsection{Thermogravimetric analysis}

Thermal analysis curves of TGA and corresponding derivative thermos-gravimetric (DTG) furnished valuable information concerning the structural composition of OR-NOM and SRHA as shown in Fig. 1(a) to (c) (Seo et al., 2011; Young and LeBoeuf, 2000). DTG curves of all samples show an initial weight loss between $2.4 \%$ and $8.1 \%$ as temperature increased from 30 to $100{ }^{\circ} \mathrm{C}$, corresponding to sample dehydration. The weight loss pattern shows the samples undergo different thermal degradation steps, indicating differences in composition. Over the range of $150{ }^{\circ} \mathrm{C}$ to $570{ }^{\circ} \mathrm{C}$ a mass loss of $34 \%$, and $54 \%$ were observed in two successive stages for OR-NOM-Jan and OR-NOM-July, respectively (Fig. 1(a) and (b)). In contrast, the TGA study of SRHA) showed a single stage sharp weight loss that started $\sim 390{ }^{\circ} \mathrm{C}$ and ended at $473{ }^{\circ} \mathrm{C}$ (Fig. 1(c)).

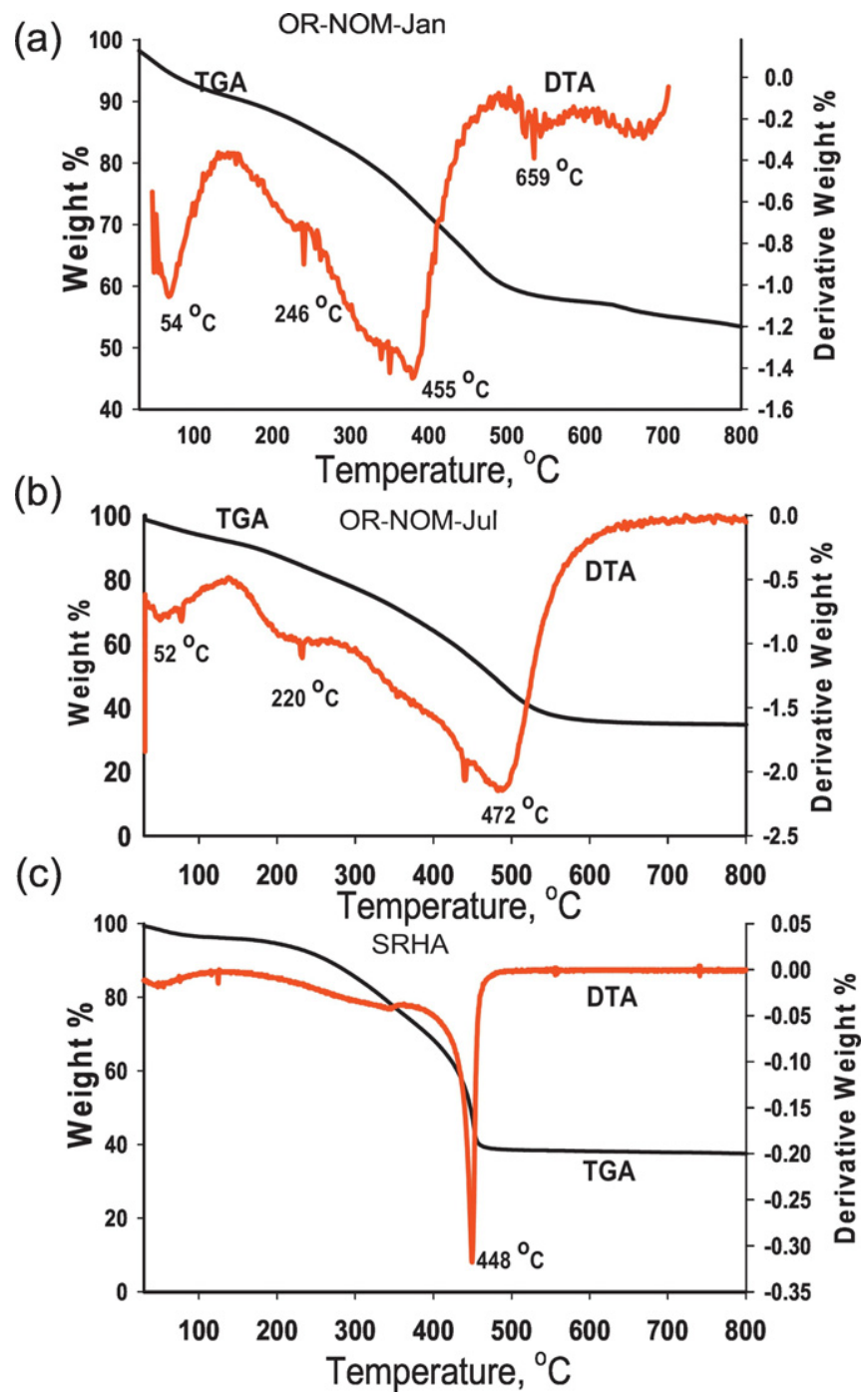

Fig. 1. Thermogravimetric (TGA) and differential thermal analysis (DTA) of natural organic matter (NOM), (a) Winter collected from the Ohio River, OR-NOM-Jan, (b) July collected form the Ohio River, OR-NOM-July, and (c) SRHA. Sample average weight was $5 \mathrm{mg}$, initial temperature $=30{ }^{\circ} \mathrm{C}$, air flow was $20 \mathrm{ml} / \mathrm{min}$, for heating rate $=10^{\circ} \mathrm{C} / \mathrm{min}$ Pan Type: Platinum

The first moderate change of weight for OR-NOM-Jan was at observed at $246{ }^{\circ} \mathrm{C}$, and for OR-NOM-July at $220^{\circ} \mathrm{C}$. Weight changes at these temperatures can be caused by thermal combustion of polysaccharides, decarboxylation of acidic groups, dehydration of hydroxylate aliphatic structures (Pietro and Paola, 2004), or transformation and oxidation of small molecules (Kolokassidou et al., 2007). SRHA was stable up to $200^{\circ} \mathrm{C}$. The maximum rate of weight loss, shown in the DTG curve, for OR-NOM-Jan and OR-NOM-July were observed at $458^{\circ} \mathrm{C}$ and $472{ }^{\circ} \mathrm{C}$, respectively; whereas for SRHA, this value was lower $\left(448{ }^{\circ} \mathrm{C}\right)$. These minima correspond to the range of $450-480^{\circ} \mathrm{C}$, which is related to the combustion of aromatic structures, the cleavage of $\mathrm{C}-\mathrm{C}$ bonds (Peuravuori et al., 1999). This leads to depolymerization, cyclization reactions, and thermal cracking of higher molecular weight polynuclear systems, such as carboxylic and phenolic groups (Shurygina et al., 1971). For DTG losses around $450{ }^{\circ} \mathrm{C}$, thermal degradation can also involve the presence of long chain hydrocarbons and nitrogen compounds (Iordanidis et al., 2001). SRHA has a more significant DTG weight loss at a narrower temperature range at this range compared to the OR-NOM samples. The difference in DTG response may be explained by the difference in processing between the samples, whereas the SRHA is fractionated by XAD resin adsorption and the OR-NOM samples consist of the whole NOM which contains fulvic substances and other smaller 
molecules. The ash content of the OR-NOM-Jan, OR-NOM-July, and SRHA, which are determined from the minimum of the TGA curve at high temperature, are 54\%, 34\% and 37\%, respectively. High ash has been previously reported in RO isolation of some winter and spring NOM samples that could be result of high Si content (Maurice et al., 2002). The difference in the thermal degradation of the three NOM samples strongly suggests that differences in composition, structure, and functional groups are caused by preparation methods used where SRHA was fractionated, and $\mathrm{OH}$ was whole.

\subsection{Fourier transfer infrared spectroscopic (FTIR) analysis of NOM}

Detailed interpretation of FTIR spectra of the structure of NOMs tested is challenging because of the high amount of overlapping of individual absorptions at different vibrational modes at different functional groups. The FTIR spectra of the OR-NOM samples and SRHA are overlaid in Fig. 2(a). While the spectra of the OR-NOM samples have some similarities, there are distinctive differences compared to the spectra of SRHA. OR-NOM samples showed sharp peaks at $1726 \mathrm{~cm}^{-1}$, which were not observed in the SRHA and may be attributed to the carboxyl $\mathrm{C}=\mathrm{O}$ stretching absorption peak. This may be because of the higher content of fulvic acid in OR-NOM that contributes to higher carboxyl group content. The $\mathrm{C}-\mathrm{H}$ stretch of the aliphatic group was shown to exist in the $1470-1410 \mathrm{~cm}^{-1}$ range. For OR-NOM-July, the peak observed at $1410 \mathrm{~cm}^{-1}$ was higher than that of the OR-NOM-Jan, implying that the higher water temperature and the increased organics degradation potential in July led to an increased hydrophilic characteristic. The peak in the range $1250-1000 \mathrm{~cm}^{-1}$ indicates $\mathrm{C}-\mathrm{O}$ stretching and the presence of hydrophilic neutral compounds. Comparatively, the peak in the $880-750 \mathrm{~cm}^{-1}$ range (795 $\mathrm{cm}^{-1}$ for OR-NOM-July and $802 \mathrm{~cm}^{-1}$ for OR-NOM-Jan) indicates an $\mathrm{O}-\mathrm{H}$ functional group attached to a carboxyl group and the presence of hydrophobic substances. These results indicate that the OR-NOM consists of both hydrophobic and hydrophilic substances. The FTIR spectrum of SRHA showed higher intensity and saturation in the range of $3600-3200 \mathrm{~cm}^{-1}$ with two peaks at 3398 and $3265 \mathrm{~cm}^{-1}$ while both OR-NOM samples resulted in only a broad absorption spectrum and no distinct peaks in this range. The SRHA peak at $1620 \mathrm{~cm}^{-1}$ can be attributed to aromatic $\mathrm{C}=\mathrm{C}$ double bond stretching, conjugated with $\mathrm{C}=\mathrm{O}$ and $\mathrm{COO}-$, which was found to be around $1640 \mathrm{~cm}^{-1}$ (Giovanela et al., 2004). The peak at $1387 \mathrm{~cm}^{-1}$ can be attributed to $-\mathrm{CO}-\mathrm{CH}_{3}$ and possibly nitrate. The $1207 \mathrm{~cm}^{-1}$ peak indicates nitrates $\left(\mathrm{R}-\mathrm{O}-\mathrm{NO}_{2}\right),=\mathrm{C}-\mathrm{O}-\mathrm{C}$ groups, and possibly C-O of phenolic groups (Baes and Bloom, 1989).

The compositional difference between SRHA and OR-NOM is a result of the origin and the method used to recover them from environmental matrices. To create SRHA, the International Humic Substances Society IHSS concentrated the NOM using reverse osmosis followed by isolating the humic substances from natural water using XAD-8 resin adsorption. In this method, the NOM was initially fractionated into hydrophobic and hydrophilic fractions. Subsequently, the hydrophobic fraction was eluted from the resin by an alkaline extraction, followed by precipitation of humic acid at low $\mathrm{pH}$ and a desalting step to obtain fulvic acid. The humic acid and fulvic acid that are isolated in this method thus contain hydrophobic organic acids. Comparatively, the OR-NOM was concentrated using RO membrane technology and directly lyophilized, maintaining a whole mixture of the hydrophobic and hydrophilic acids in addition to the other soluble organic solutes that are present in natural waters. These differences between SRHA and OR-NOM confirmed that using SRHA to study the effect of NOM for drinking water related assessment might not be sufficient to represent the natural conditions of the environment.

\subsection{Solid state nuclear magnetic resonance (sSNMR)}

Solid-state NMR spectroscopy was used to obtain qualitative information on organics carbon structural distributions of NOMs. By using high concentration of the solid sample, we were able to obtain results in superior sensitivity of solid-state ${ }^{13} \mathrm{C}$ NMR spectra including spectral editing of strongly overlapping bands. However, ${ }^{1} \mathrm{H}$ NMR spectra do not lend themselves to such quantification due to peak overlap of functional groups and domains on a 0.5-30 nm scale (Leenheer et al., 1997). Thus, quantitative determination of various structures in NOM is a subjective to the judgement of the analyst. The uncertainties of these chemicalshift an isotropic numbers and the experimental errors could be of the same order of magnitude The SRHA, however, definitely shows a significant qualitative difference compared to both OR-NOM samples. The aromatic to aliphatic ratio seems to be higher in both NOMs as opposed to that in the SRHA. Similar profile of humic acid were reported (Cook and Langford, 1998; Sardessai and Wahidullah, 1998). ${ }^{1} \mathrm{H}$ NMR spectra of NOM samples and SRHA were dissolved in $\mathrm{D}_{2} \mathrm{O}$ at pH 7. Optimum condition for the experiments proton-lattice relaxation times were obtained from previous developed method (Thorn et al., 1992). Differences in structural signatures among both NOMs and SRHA fraction were observed as shown in Fig. 2(b) and (c). Structural assignments for ${ }^{1} \mathrm{H}$ NMR spectra included chemical shift range (a) 0.6-1.4 ppm for $\mathrm{R}-\mathrm{CH} 3$, (b) 0.9-1.2 ppm $\mathrm{O}=\mathrm{C}-\mathrm{C}-\mathrm{CH}_{3}$ (c) 1.9-2.1 ppm, methyl ketones, $\mathrm{O}=\mathrm{C}-\mathrm{CH} 3$, (d) 5.0-6.4 ppm, $\mathrm{C}=\mathrm{C}-\mathrm{H}$, (e) 6.4-9.5 ppm, aromatic, $\mathrm{H}$-ortho carboxylic acids. Other researchers have identified the following major spectral bands for NOM fractions for ${ }^{13} \mathrm{C}$ NMR, which includes (a) 0-50 ppm, representing mainly aliphatic or paraffinic carbon chains; (b) 50-75 ppm, representing primarily methoxyl $\left(\mathrm{OCH}_{3}\right)$ groups, and 75-112 ppm for carbohydrate RC-OH or RC-OR functional groups; (c) 112-145 ppm, as a result of resonance from aromatic carbons; (d) 145-163 ppm, representing the phenolic groups; and (a)

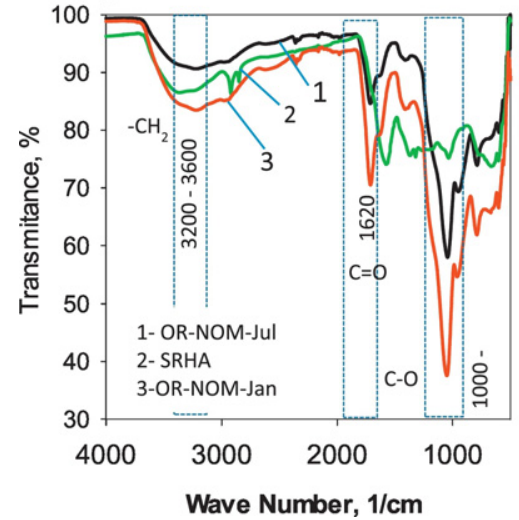

(b)

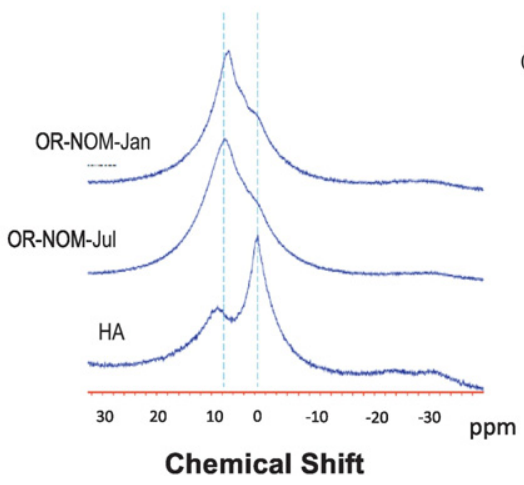

(c)

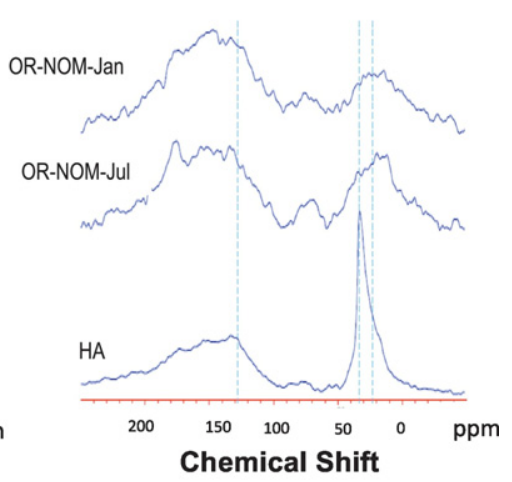

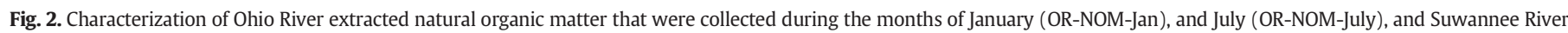
humic acid (SRHA) using (a) Fourier transfer infrared spectra, (b) NMR spectra ${ }^{1} \mathrm{H}$ DP MAS, and (c) ${ }^{13} \mathrm{C} \mathrm{CP}$ Mass spectra at $10 \mathrm{kHz}$. 
(e) 163-180 ppm, corresponding to carboxylic, carbonyl, amine, and estercarbons in NOM (Cook and Langford, 1998; Chen et al., 1996; Malcolm, 1989; Mao et al., 2000; Newman and Tate, 1991; Newman et al., 1987; Xing and Chen, 1999).

The SRHA displayed a sharp peak with relatively larger amount of aliphatics 0.9-14 ppm for ${ }^{1} \mathrm{H}$ NMR, and 30-40 ppm for ${ }^{13} \mathrm{C}$ NMR. SRHA contain small amounts of aromatic carbon at $\sim 130 \mathrm{ppm}{ }^{13} \mathrm{C}$ NMR spectra and $\sim 9 \mathrm{ppm}$ for the ${ }^{1} \mathrm{H}$ DP Mass. The NMR spectra of SRHA supports the main functional groups identified on FTIR spectra. The amount is close to the average aromatic carbon content of most humic substances ( 35\%) (Malcolm, 1989). SRHA showed relatively low amounts of carbohydrate functional groups. Proton NMR showed that the two NOMs have significant amounts of aromatics $\sim 9 \mathrm{ppm} .{ }^{13} \mathrm{C}$ NMR showed paraffinic carbon chains 10-20 ppm and slightly larger amounts methoxyl $\left(\mathrm{OCH}_{3}\right)$ carbon at $\sim 55 \mathrm{ppm}$ than the SRHA. Both, OR_NOM samples showed relatively high amounts of carboxylic and phenolic carbons 145-180 ppm fractions. On the basis of ${ }^{1} \mathrm{H}$ DPMAS and ${ }^{13} \mathrm{C}$ CPMAS spectra collected we concluded that the two samples of OR-NOM-Jan and OR-NOM-July have a lot of structural similarities.

\subsection{The influence of OR-NOM on the $\zeta$-potential of $\mathrm{CeO}_{2} \mathrm{NPS}$}

The effect of NOM on the electrophoretic stability of $\mathrm{CeO}_{2}$ was studied by measuring the $\zeta$-potential in the presence of increasing concentrations of OR-NOM $(1,5,10 \mathrm{ppm})$ at various ionic strengths $(3,10,50$ and $100 \mathrm{mM} \mathrm{NaCl}$ ) (Fig. 3). The $\zeta$-potential of $\mathrm{CeO}_{2}$ NPs became less negative with increasing ionic strength because of the compression of electrical double layers, while increasing NOM concentration resulted in a more negative surface of the $\mathrm{CeO}_{2} \mathrm{NPs}$. The $\mathrm{CeO}_{2}$ NPs were more sensitive to the presence of summer collected NOM, resulting in lower $\zeta$-potential.

At the same NOM level, $\mathrm{CeO}_{2}$ NPs are more stable in the presence of OR-NOM-July compared to OR-NOM-Jan, reflected by a larger absolute value of $\zeta$-potential. This ionic stabilization effect of NOMs can be seen in the example as at the concentration of $1 \mathrm{ppm}$, for OR-NOM-Jan, the $\zeta$-potential of $\mathrm{CeO}_{2}$ increased from $-43 \mathrm{mV}$ at $1 \mathrm{mM} \mathrm{NaCl}$ to $-32 \mathrm{mV}$ at $100 \mathrm{mM} \mathrm{NaCl}$; while for OR-NOM-July, it increased from $-46 \mathrm{mV}$ at $1 \mathrm{mM} \mathrm{NaCl}$ to $-35 \mathrm{mV}$ at $100 \mathrm{mM} \mathrm{NaCl}$. When increasing the NOM concentration, a general increase in the absolute value of $\mathrm{CeO}_{2} \zeta$ potential was observed at most ionic values. However, the increase was more significant from 1 to $5 \mathrm{ppm}$, than from 5 to $10 \mathrm{ppm}$. This may be because at the higher NOM concentrations the adsorption of NOM to the NPs surface reached saturation, so further NOM increase does not contribute a significant change.

\subsection{Influence of $\mathrm{NOM}$ on the stability of $\mathrm{CeO}_{2}$ nanoparticle}

Homoaggregation of NPs involve collisions between particles that is governed by Brownian diffusion and attachment). $\mathrm{CeO}_{2} \mathrm{NPs}$ have high surface-to-volume ratio giving them high surface energies that cause thermodynamic instability and collisions results in aggregation (Christian et al., 2008). Although NP suspension is thermodynamically unstable, the aquatic environment could create barriers that result in steric and electrostatic stabilization. Aggregation of NPs is influenced by NPs concentration, the presence, type and concentration of NOMs. NOM, in general, tends to stabilize NPs and hinder aggregation, except under aquatic conditions that favor bridging flocculation. Specific interactions $\mathrm{CeO}_{2} \mathrm{NP}$ to NOMs from different sources could be highly dependent on the particular chemical nature of the NOM and how they affect the extent of stabilization (Li and Chen, 2012). NOM is a heterogeneous mixture of organic compounds having different characteristics depending on the source and age. Aggregation of $\mathrm{CeO}_{2} \mathrm{NPs}(30 \mathrm{mg} / \mathrm{l})$ decreased by order of magnitude when $1 \mathrm{mg} / \mathrm{l}$ of NOMs and $10 \mathrm{mM} \mathrm{NaCl}$ were dissolved and allowed to reach equilibrium over $8 \mathrm{~h}$ (Fig. 4(a), and (b). Further increase in NOM concentrations to $5 \mathrm{mg} / \mathrm{l}$ resulted in a decrease in $\mathrm{CeO}_{2}$ aggregation by a factor of 9 that was based on the increased in average particle size. This reduction in the aggregation of $\mathrm{CeO}_{2}$ was less effective when same amounts of SRHA were added. Further increase in NOM or SRHA concentrations did not make any difference in the aggregation of $\mathrm{CeO}_{2}$ particles (Fig. 4(a)-(c)). The OR-NOMs reduced the aggregations further than humic acid for the same concentration range (Fig. 4(b)). The OR-NOM has a marked stabilizing effect at concentrations as low as $1 \mathrm{mg} / \mathrm{l}$, and stabilization effect was independent of NOM concentrations above $5 \mathrm{mg} / \mathrm{l}$. This data confirms previously reported studies (Lv et al., 2014). However, the effect of the three NOMs differs.

The effects of NOM concentrations on the NPs aggregation were investigated for a solution with $10 \mathrm{mM} \mathrm{NaCl}, 1 \mathrm{mg} / \mathrm{l}$ of NOMs and $\mathrm{CeO}_{2}$ NPs concentrations of $10 \mathrm{mg} / \mathrm{l}$, and $30 \mathrm{mg} / \mathrm{l}$ as shown in Fig. 4(d) and (e), respectively. As the concentration of $\mathrm{CeO}_{2} \mathrm{NPs}$ was increased to
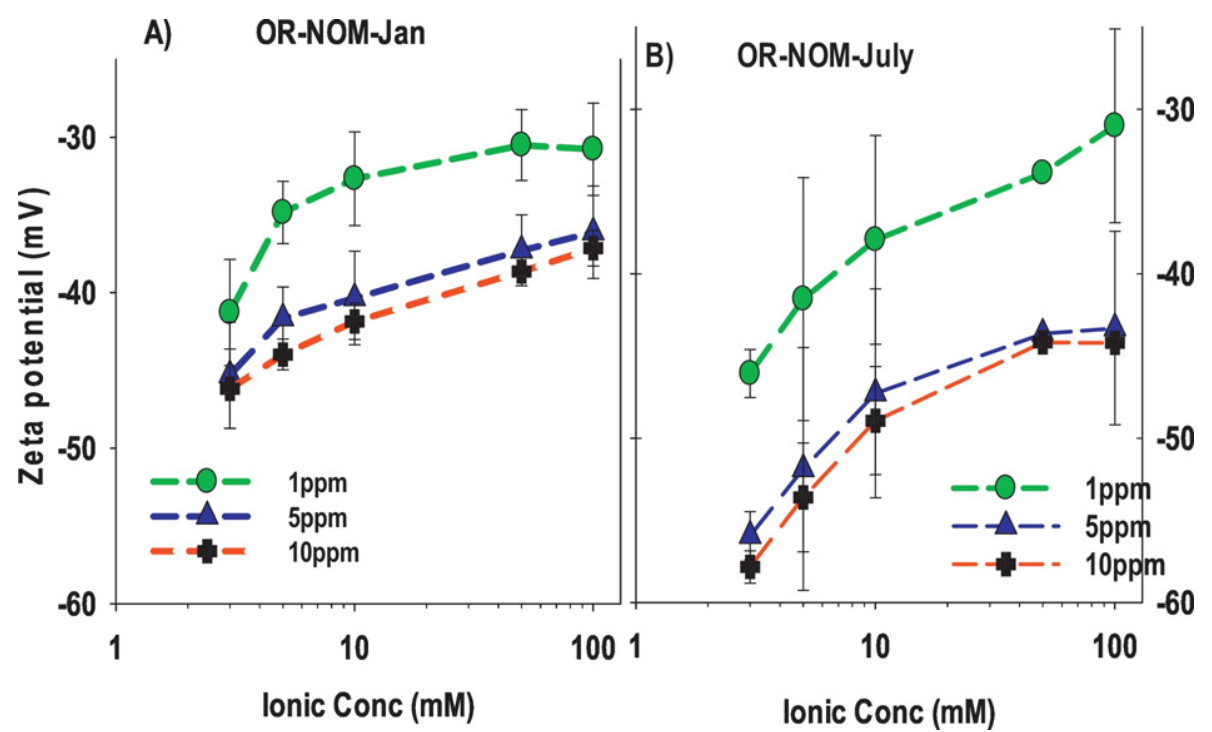

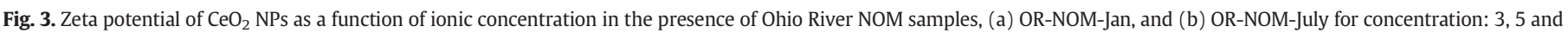
$10 \mathrm{mg} / \mathrm{l}$. 

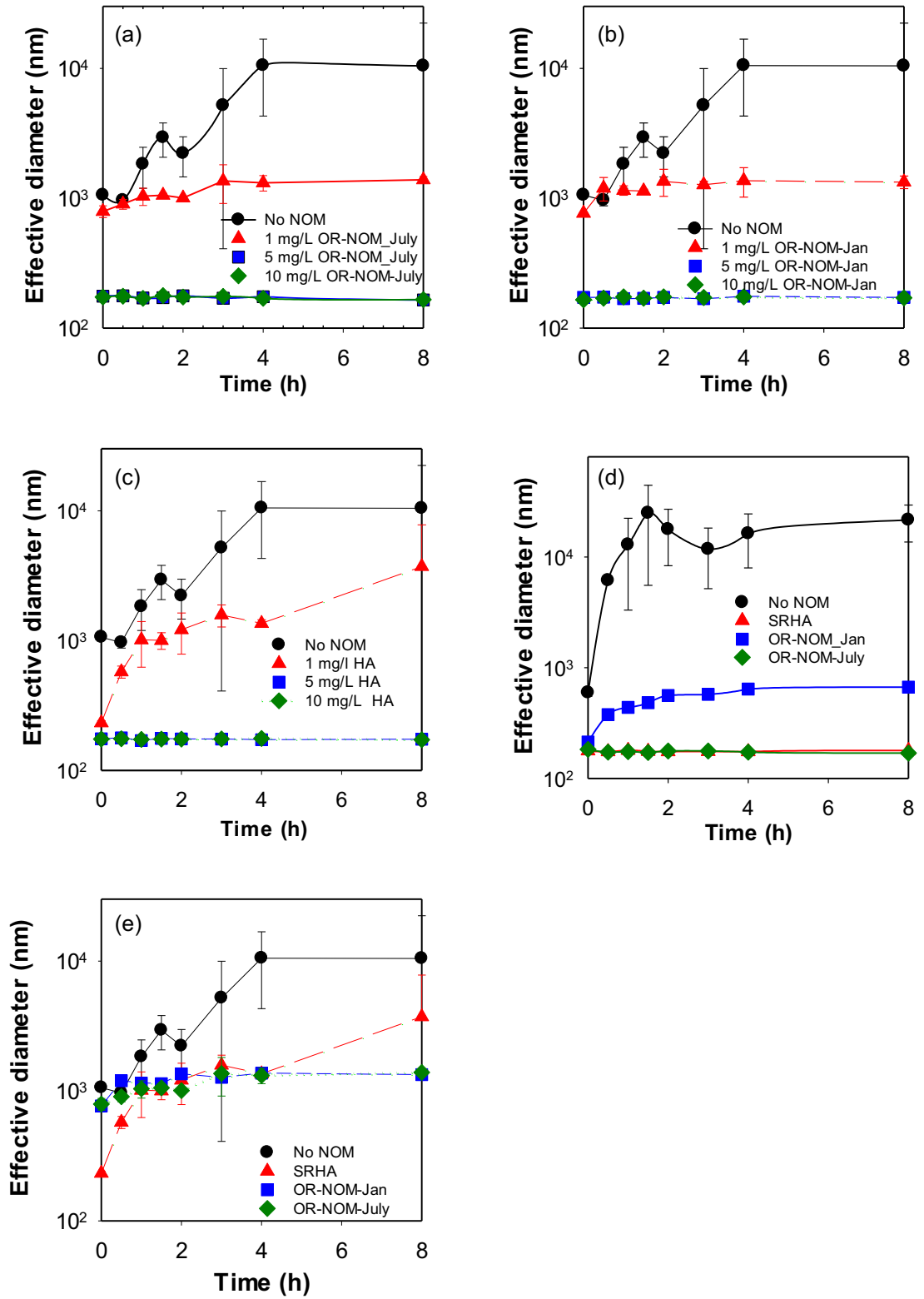

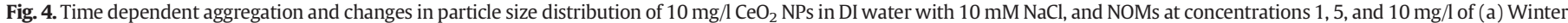

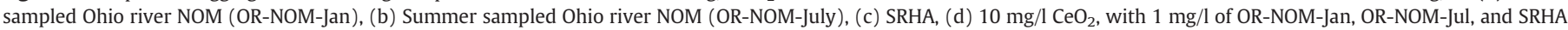
(e) $30 \mathrm{mg} / \mathrm{l} \mathrm{CeO}_{2} \mathrm{Cl}$, with $1 \mathrm{mg} / \mathrm{l}$ of OR-NOM-Jan, OR-NOM-Jul, and SRHA.

$30 \mathrm{mg} / \mathrm{l}$ (Fig. 4(e)) the effective diameters of the aggregate increased eightfold. But, the increased in aggregation was not linearly proportional to NP concentrations. The higher $\mathrm{CeO}_{2} \mathrm{NPs}$ concentration involves increased particle collisions. On the other hand, increased concentration of NOMs reduced aggregation. This suggests that the stabilization mechanisms of ionic strength and NOMs acting on $\mathrm{CeO}_{2} \mathrm{NPs}$ were the combined effects of electrostatic effects of water chemistry and steric stabilization confirming due to NOMs (Chen et al., 2012; Wagner et al., 2014). OR-NOM-Jul showed a more pronounced effect in stabilizing $\mathrm{CeO}_{2}$ particles at $30 \mathrm{mg} / \mathrm{l}$ concentration than SRHA and OR-NOM-Jan. The difference in the type of NOMs affecting NP stability has been noted in previous studies (Lanphere et al., 2014). ORNOM-July displayed higher aromatic content as indicated from spectroscopic studies in the previous section. The aromatic fraction of the humic and fulvic acids have increased sorption with NPs and nanotubes by $\pi-\pi$ interaction (Chen and Elimelech, 2007; Hyung and Kim, 2008).

\subsection{Transport of $\mathrm{CeO}_{2}$ NPS in porous media in the presence of OR-NOM}

The transport breakthrough curves and retention profiles of $\mathrm{CeO}_{2} \mathrm{NPs}$ at $\mathrm{pH} 6.8$, increasing ionic strength $(3,5$, and $10 \mathrm{mM})$, and increasing NOM concentration (1,5, and $10 \mathrm{ppm}$ ) are shown in Fig. 5(a) to (c), for OR-NOM samples. In our previous study (Lu et al., 2013), the absence of NOM and near-neutral solution $\mathrm{pH}$ showed partial breakthrough profile of $\mathrm{CeO}_{2} \mathrm{NPs}$ when the ionic concentration was greater than $1 \mathrm{mM}$. The normalized breakthrough concentration $\left(C / C_{0}\right.$, where $C$ is the effluent concentration, and $C_{0}$ is the effluent concentration) plateau value were consistently less than 1 (Fig. 5(a)). However, in the presence of NOM, $\mathrm{CeO}_{2} \mathrm{NPs}$ quickly reached full breakthrough $\left(C / C_{0}=1\right)$ in a $3 \mathrm{mM}$ ionic concentration, even at the lower NOM concentration of $1 \mathrm{ppm}$, confirming the stabilizing effect of dissolved NOM (Fig. 5(a) and (b)).

At $5 \mathrm{mM}$ ionic concentration and the 5 and 10 ppm OR-NOM concentrations, $\mathrm{CeO}_{2} \mathrm{NPs}$ gradually reached the full breakthrough at 12 pore volume. At $1 \mathrm{ppm}$ NOM concentration, $\mathrm{CeO}_{2} \mathrm{NPs}$ reached a partial 

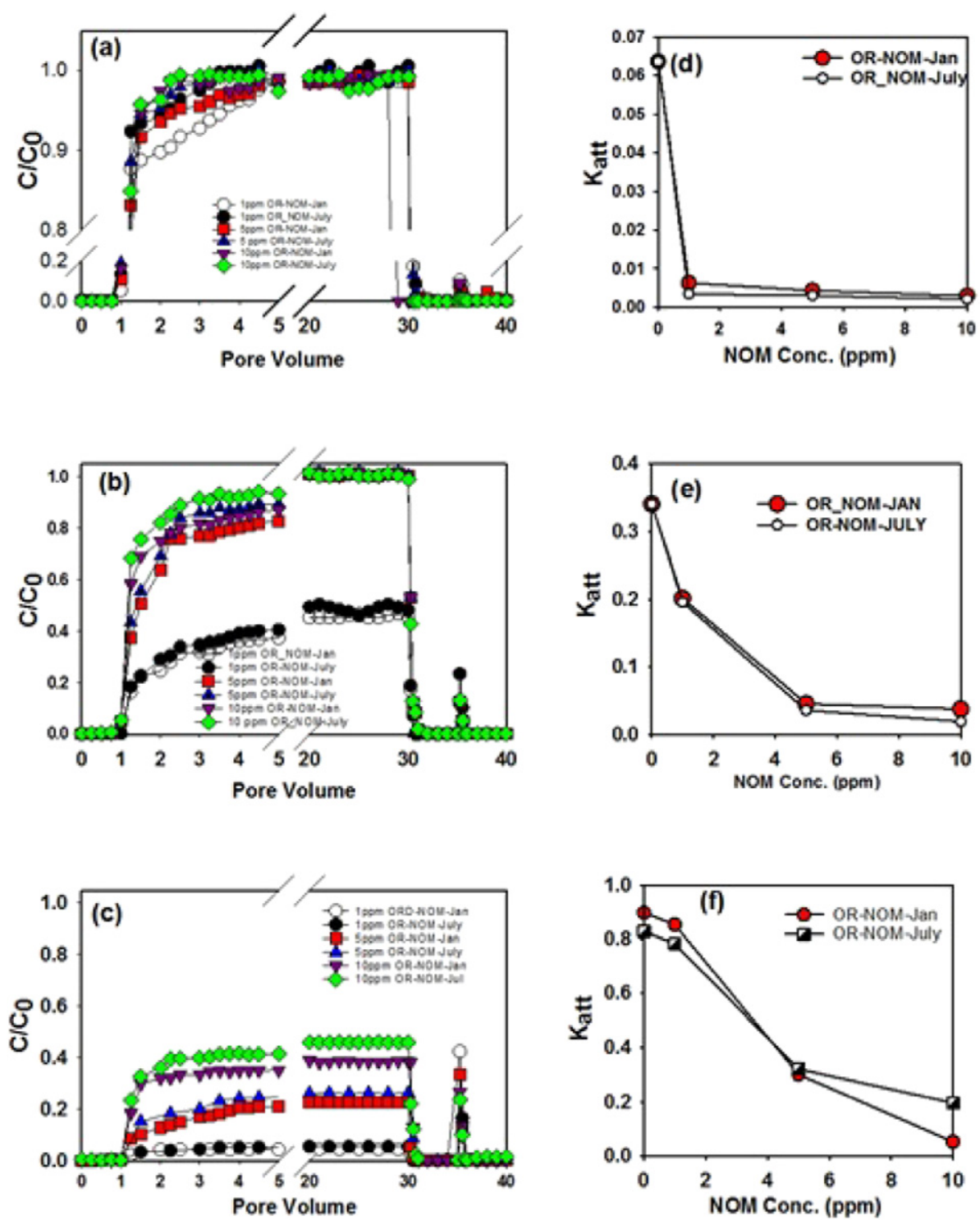

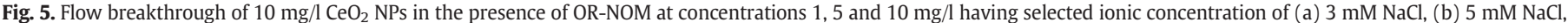
(c) $10 \mathrm{mM} \mathrm{NaCl}$, and the corresponding attachment efficiency for ionic concentration, (d) $3 \mathrm{mM} \mathrm{NaCl}$, (e) $5 \mathrm{mM} \mathrm{NaCl}$, (f) $10 \mathrm{mM} \mathrm{NaCl}$.

breakthrough with a plateau of approximately 0.48 for both OR-NOMJan and OR-NOM-July. For 3 and $5 \mathrm{mM}$, ionic concentration and a given NOM concentration, the type of NOM (Jan or July) did not change the plateau of the breakthrough, but only affected the shape and rate of the initial breakthrough. The $\mathrm{CeO}_{2}$ breakthrough occurred after 1-3 pore volumes, where the original breakthrough rate increased with increasing NOM concentration. Also, the breakthrough of $\mathrm{CeO}_{2}$ was somewhat faster in the presence of OR-NOM-July as compared with OR$\mathrm{NOM}-J a n$. At a $10 \mathrm{mM}$ ionic concentration, $\mathrm{CeO}_{2}$ NPs had a partial breakthrough, starting around 1 pore volume and slowly reaching a plateau. The plateau concentration increased with increasing NOM concentration. Furthermore, the two higher NOM concentrations resulted in a higher plateau in the presence of the OR-NOM-July compared to the OR-NOM-Jan. Sharp peaks were observed for $\mathrm{CeO}_{2} \mathrm{NPs}$ during the rinse phase at approximately 35 pore volumes. The peak intensity of the rinse phase was higher when the plateau value of the breakthrough curve was lower in the deposition phase indicating that loosely adsorbed NPs washed out when the water chemistry changed.

The maximum effluent concentration normalized with the input concentration decreased with increasing ionic strength and increased with increasing NOM concentrations when other conditions remained the same. Both OR-NOM samples resulted in differences in the transport of $\mathrm{CeO}_{2}$ NPs that were more significant at higher ionic and NOM concentrations. OR-NOM-July showed a higher stabilizing effect for $\mathrm{CeO}_{2} \mathrm{NPs}$, which can be explained by the higher organic carbon content. ORNOM-July also has a more $\mathrm{C}-\mathrm{H}$ stretch of the aliphatic group, which contributes in stabilizing $\mathrm{CeO}_{2} \mathrm{NPs}$.

At an ionic strength of 3 and $5 \mathrm{mM}$, the breakthrough profile of $\mathrm{CeO}_{2}$ NPs is in agreement with the $\zeta$-potential measurements. For instance, in $5 \mathrm{mM}$ ionic strength solution, when OR-NOM-July concentration increased from 1 to $5 \mathrm{ppm}$, the $\zeta$-potential of the $\mathrm{CeO}_{2} \mathrm{NPs}$ decreased from $-41.5 \mathrm{mV}$ to $-53.6 \mathrm{mV}$ and the plateau value of the breakthrough curves of $\mathrm{CeO}_{2}$ increased from 0.48 to 0.98 . The same trend was observed for OR-NOM-Jan. This behavior is believed to result from an increased electrostatic repulsive interaction which prevents the $\mathrm{CeO}_{2}$ NPs from attaching within the column, and therefore exiting in the effluent. This phenomenon is in qualitative agreement with the DLVO theory of colloidal stability. On the other hand, the $\zeta$-potentials of the $\mathrm{CeO}_{2}$ $\mathrm{NPs}$ at $10 \mathrm{mM} \mathrm{NaCl}$ concentration changed only minimally with the increase in NOM from 5 to $10 \mathrm{ppm}$, while the maximum normalized 
effluent concentration of the breakthrough curve increased from 0.23 to 0.45 in the presence of OR-NOM-July and from 0.20 to 0.36 in the presence of OR-NOM-Jan. These results cannot be explained in the framework of the classic DLVO theory.

The transport and retention profile of $\mathrm{CeO}_{2} \mathrm{NPs}$ through porous media in the presence of SRHA is included in a Supplementary material in Fig. S2, and the corresponding attachment efficiency values are shown in Fig. S3. The effect of SRHA on the transport of the $\mathrm{CeO}_{2} \mathrm{NPs}$ is similar to the OR-NOM samples but resulted in less particle stabilization and higher maximum normalized effluent concentrations. For example, at the same ionic concentration and NOM concentration, the breakthrough curves for $\mathrm{CeO}_{2} \mathrm{NPs}$ showed higher maximum normalized effluent concentrations in the presence of SRHA as compared to OR-NOM, consequently yielding higher $K_{\text {att }}$ values. This indicates using SRHA as a model NOM to study the transport and retention of NPs in drinking water relevant sand filters may over-estimate the facilitating effect of NOM.

\subsection{Modified DLVO theory and the attachment efficiency of $\mathrm{CeO}_{2} \mathrm{NPs}$ in the presence of OR-NOM}

The breakthrough curves of $\mathrm{CeO}_{2} \mathrm{NPs}$ were used to calculate the attachment efficiency $\left(k_{\text {att }}\right)$ in packed beds, which was experimentally determined for each of the test conditions following a previously described procedure (Li et al., 2011) and provided in the supplementary material. Fig. 5(d), (e), and (f) summarizes $K_{a t t}$ as a function of NOM concentration at each ionic strength. The increasing NOM concentrations decreased the attachment efficiency of $\mathrm{CeO}_{2}$ NPs, becoming more pronounced as the ionic strength increased above $3 \mathrm{mM} \mathrm{NaCl}$. Therefore, the mobility and transport of the $\mathrm{CeO}_{2} \mathrm{NPs}$ were increased due to the adsorption of NOM to the NP surface. The stabilizing and mobilizing effect of OR-NOM-July were more pronounced than those of OR-NOM-Jan. As a result, the stability and mobility of $\mathrm{CeO}_{2}$ was largely dependent on the aqueous concentration of NOM, and the seasonal change of NOM, especially at higher ionic strength.

To analyze the impact of NOM on the transport and deposition behavior of $\mathrm{CeO}_{2} \mathrm{NPs}$ further, the interaction energy between the $\mathrm{CeO}_{2}$ NPs and the sand surfaces were calculated for each experimental condition. Since the traditional DLVO theory was insufficient to describe the transport and deposition of $\mathrm{CeO}_{2} \mathrm{NPs}$ in the sand filters at $10 \mathrm{mM}$ $\mathrm{NaCl}$, as discussed previously, a steric repulsive energy was added to the total interaction energy to better describe the energy profile between $\mathrm{NOM}$ coated $\mathrm{CeO}_{2} \mathrm{NPs}$ and sand surfaces. Steric repulsion between two surfaces results from volume restriction and osmotic effects (Brown and Jaffé, 2001; Petryshyn et al., 2010). The former takes place from the reduction of space in the zone between particle surfaces; the later arises from the high concentration of adsorbed charged macromolecules in the region between the surfaces as they approach each other. Electrostatic and steric repulsion forces inhibit deposition of particles to grain surfaces.

The modified DLVO interaction energy profiles for $\mathrm{CeO}_{2} \mathrm{NPs}$ at $3 \mathrm{mM}$ $\mathrm{NaCl}$, in the presence of $5 \mathrm{ppm}$ and $10 \mathrm{ppm}$ OR-NOM-July are shown in Fig. 6. The results show that for the traditional DLVO theory, which includes only double layer repulsion and van der Waals attraction, the interaction energy profile for 5 ppm NOM (A) and 10 ppm NOM (B) were very close. The DLVO theory demonstrates the existence of a repulsive energy barrier at $12 \mathrm{kT}$ where the DLVO curve peaks around $5 \mathrm{~nm}$ and a shallow secondary minimum of $-6 \mathrm{kT}$, implying moderate deposition conditions. However, the enhanced breakthrough when the NOM concentration was increased to $10 \mathrm{ppm}$ is not reflected in the DLVO curve. Adding the steric repulsive energy to the DLVO theory resulted in a shallower secondary minimum and a greater energy barrier because of the adsorption of OR-NOM to the $\mathrm{CeO}_{2} \mathrm{NPs}$. An apparent increase in the primary energy barrier is shown for $10 \mathrm{ppm}$ NOM $(27 \mathrm{kT})$ compared to $5 \mathrm{ppm}$ NOM ( $18 \mathrm{kT}$ ), indicating that it is less likely for $\mathrm{CeO}_{2} \mathrm{NPs}$ to overcome the primary energy barrier and be deposited onto the sand
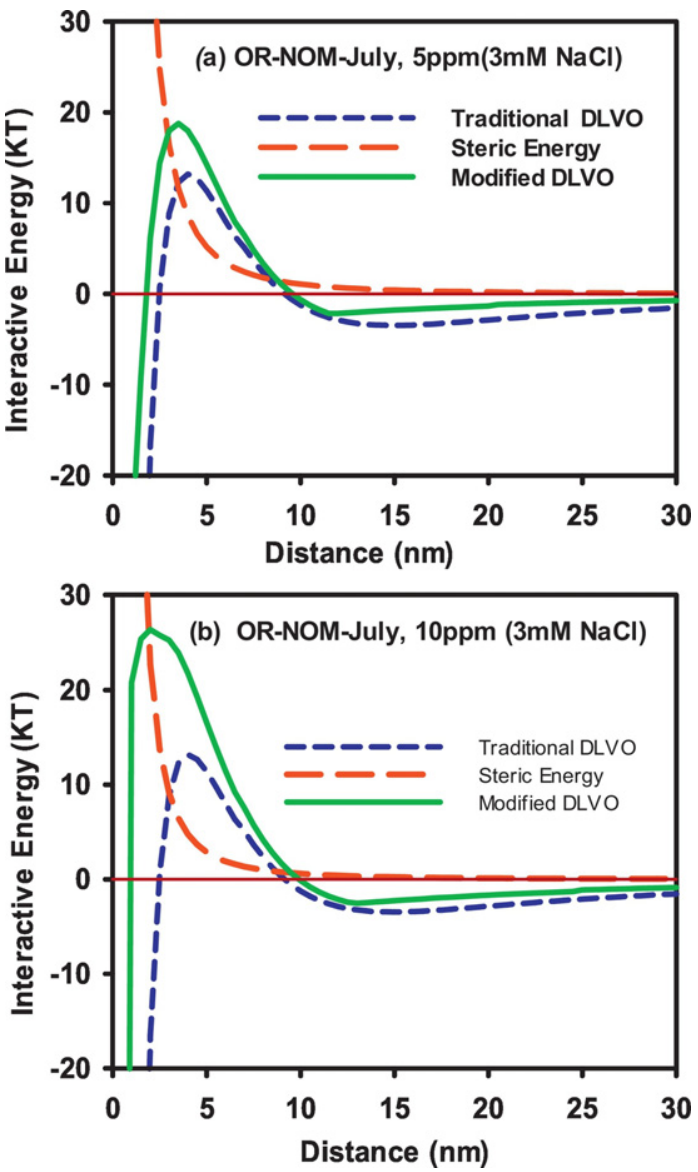

Fig. 6. Calculated modified DLVO interaction energy values as $\mathrm{CeO}_{2} \mathrm{NPs}$ approaching sand surface at the ionic concentration of $10 \mathrm{mM} \mathrm{NaCl}$, in the presence of (a) $5 \mathrm{mg} / \mathrm{l} \mathrm{OR-NOM-}$ July, and (b) $10 \mathrm{mg} / \mathrm{l} \mathrm{OR-NOM-July.}$

surface, which explains the enhanced breakthrough that was observed in the transport column studies.

The presence of NOM in the NP suspensions clearly affected the maximum normalized effluent concentrations in the transport study as well as the attachment efficiency and maximum transport distance. OR-NOM clearly increased the stability of $\mathrm{CeO}_{2} \mathrm{NPs}$ in water as the absolute $\zeta$-potential increased with an increasing NOM concentration. However, there was a difference in the $\zeta$-potential of $\mathrm{CeO}_{2} \mathrm{NPs}$ depending on the type of NOM mixed that was collected during January or July, resulting in a different breakthrough profile at a $10 \mathrm{mM}$ ionic strength. This difference in $\zeta$-potential is related to the proportion of humic acid to fulvic acid present in these two NOM types and the TOC level. An increase in the $\zeta$-potential increased the electrostatic repulsion, which in turn reduced aggregation and enhanced transport of NPs through the sand column. The adsorption of NOM stabilized $\mathrm{CeO}_{2}$ NPs against van der Waals attractive forces. The repulsive forces were a combination of electric particle surface charge or electrostatic double layer repulsions, and the steric repulsion forces generated from the adsorption of long-chain-charged NOM molecules on the surface of NPs.

\section{Conclusion}

This study characterized OR-NOM during winter and summer times, and demonstrated the effects of these NOM samples on stability and transport of $\mathrm{CeO}_{2} \mathrm{NPs}$ in saturated porous media. OR-NOM samples that were characterized by thermal analysis, FTIR, solid state NMR spectrometer and elemental analysis showed to have structural and compositional differences from SRHA. This study explored the effects of OR- 
NOM in enhancing the transport and breakthrough of $\mathrm{CeO}_{2}$ NPs in moderate (1-10 mM) ionic strength solutions. The enhancement in stability and transport appear to be dominated by the altered electrokinetic properties of the $\mathrm{CeO}_{2} \mathrm{NPs}$. Increasing NOM concentrations, as measured by zeta potential, increased the electrostatic repulsive interaction between $\mathrm{CeO}_{2}$ NPs. As the level of NOM increases, combinations of high electrostatic and steric interaction provide further repulsive forces to stabilize and mobilize $\mathrm{CeO}_{2} \mathrm{NPs}$ in the aquatic environment. A modified DLVO theory presented in this study can qualitatively interpret the general trends of the $\mathrm{CeO}_{2} \mathrm{NPs}$ transport and retention behavior under such conditions. The effect was also compared between summer and winter collected NOM samples. Summer collected NOM showed a stronger effect in stabilizing and facilitating the transport of $\mathrm{CeO}_{2}$ NPs. The difference in chemical and physical properties between SRHA and OR-NOM suggests that SRHA may only be used to determine qualitative effects of NOM since SRHA might not represent the composition of natural organic matter of a particular environment.

\section{Disclaimer}

The views expressed in this article are those of the authors and do not reflect the official policy or position of the Unites State Environmental Protection Agency. Mention of trade names, products, or services does not convey official EPA approval, endorsement, or recommendation. This manuscript has been subjected to the Agency's review and has been approved for publication.

\section{Acknowledgment}

This project was supported in part by an appointment to the Internship/Research Participation Program at the National Risk Management Research Laboratory, Office of Research and Development, U.S. Environmental Protection Agency, administered by the Oak Ridge Institute for Science and Education through an interagency agreement between the U.S. Department of Energy and U.S. EPA. The authors are grateful for the financial support from U.S. Environmental Protection Agency under contract no. PR-C108-1170.

\section{Appendix A. Supplementary data}

Supplementary data to this article can be found online at http://dx. doi.org/10.1016/j.scitotenv.2017.07.154.

\section{References}

Akbour, R.A.t., Douch, J., Hamdani, M., Schmitz, P., 2002. Transport of kaolinite colloids through quartz sand: influence of humic acid, $\mathrm{Ca}^{2+}$, and trace metals. J. Colloid Interface Sci. 253 (1), 1-8.

Alexander, S., 1977. Adsorption of chain molecules with a polar head a scaling description. J. Phys. 38 (8), 983-987.

Apha, A., 1998. Wpcf. Standard Methods for the Examination of Water and Wastewater 20.

Asharani, P., Lianwu, Y., Gong, Z., Valiyaveettil, S., 2011. Comparison of the toxicity of silver, gold and platinum nanoparticles in developing zebrafish embryos. Nanotoxicology 5 (1), 43-54.

Badawy, A.M.E., Luxton, T.P., Silva, R.G., Scheckel, K.G., Suidan, M.T., Tolaymat, T.M., 2010. Impact of environmental conditions ( $\mathrm{pH}$, ionic strength, and electrolyte type) on the surface charge and aggregation of silver nanoparticles suspensions. Environ. Sci. Technol. 44 (4), 1260-1266.

Baes, A., Bloom, P., 1989. Diffuse reflectance and transmission Fourier transform infrared (DRIFT) spectroscopy of humic and fulvic acids. Soil Sci. Soc. Am. J. 53 (3), 695-700.

Bettini, S., Boutet-Robinet, E., Cartier, C., Coméra, C., Gaultier, E., Dupuy, J., Naud, N., Taché, S., Grysan, P., Reguer, S., 2017. Food-grade $\mathrm{TiO}_{2}$ impairs intestinal and systemic immune homeostasis, initiates preneoplastic lesions and promotes aberrant crypt development in the rat colon. Sci Rep 7.

Brown, D.G., Jaffé, P.R., 2001. Effects of nonionic surfactants on bacterial transport through porous media. Environ. Sci. Technol. 35 (19), 3877-3883.

Chen, K.L., Elimelech, M., 2007. Influence of humic acid on the aggregation kinetics of fullerene (C60) nanoparticles in monovalent and divalent electrolyte solutions. J. Colloid Interface Sci. 309 (1), 126-134.
Chen, Z., McGill, W., Dudas, M., Xing, B., 1996. $\alpha$-Naphthol sorption as regulated by structure and composition of organic substances in soils and sediments. Can. J. Soil Sci. 76 (4), 513-522.

Chen, G., Liu, X., Su, C., 2012. Distinct effects of humic acid on transport and retention of $\mathrm{TiO}_{2}$ rutile nanoparticles in saturated sand columns. Environ. Sci. Technol. 46 (13), 7142-7150.

Christian, P., Von der Kammer, F., Baalousha, M., Hofmann, T., 2008. Nanoparticles: structure, properties, preparation and behaviour in environmental media. Ecotoxicology 17 (5), 326-343.

Cook, R.L., Langford, C.H., 1998. Structural characterization of a fulvic acid and a humic acid using solid-state ramp-CP-MAS ${ }^{13} \mathrm{C}$ nuclear magnetic resonance. Environ. Sci. Technol. 32 (5), 719-725.

Cornelis, G., Kirby, J.K., Beak, D., Chittleborough, D., McLaughlin, M.J., 2010. A method for determination of retention of silver and cerium oxide manufactured nanoparticles in soils. Environ. Chem. 7 (3), 298-308.

Deshiikan, S.R., Eschenazi, E., Papadopoulos, K.D., 1998. Transport of colloids through porous beds in the presence of natural organic matter. Colloids Surf A Physicochem Eng Asp 145 (1), 93-100.

Elimelech, M., O'Melia, C.R., 1990. Kinetics of deposition of colloidal particles in porous media. Environ. Sci. Technol. 24 (10), 1528-1536.

Ghosh, S., Mashayekhi, H., Pan, B., Bhowmik, P., Xing, B., 2008. Colloidal behavior of aluminum oxide nanoparticles as affected by $\mathrm{pH}$ and natural organic matter. Langmuir 24 (21), 12385-12391.

Giovanela, M., Parlanti, E., Soriano-Sierra, E., Soldi, M., Sierra, M., 2004. Elemental compositions, FT-IR spectra and thermal behavior of sedimentary fulvic and humic acids from aquatic and terrestrial environments. Geochem. J. 38 (3), 255-264.

Goharshadi, E.K., Samiee, S., Nancarrow, P., 2011. Fabrication of cerium oxide nanoparticles: characterization and optical properties. J. Colloid Interface Sci. 356 (2), 473-480.

Hautman, D.P., Munch, D.J., 1997. Method 300.1: Determination of Inorganic Anions in Drinking Water by Ion Chromatography. EPA, Ohio.

Hyung, H., Kim, J.-H., 2008. Natural organic matter (NOM) adsorption to multi-walled carbon nanotubes: effect of NOM characteristics and water quality parameters. Environ. Sci. Technol. 42 (12), 4416-4421.

Iordanidis, A., Georgakopoulos, A., Markova, K., Filippidis, A., Kassoli-Fournaraki, A., 2001. Application of TG-DTA to the study of Amynteon lignites, Northern Greece. Thermochim. Acta 371 (1), 137-141.

Jeong, S.-W., Kim, S.-D., 2009. Aggregation and transport of copper oxide nanoparticles in porous media. J. Environ. Monit. 11 (9), 1595-1600.

Johnston, H.J., Hutchison, G., Christensen, F.M., Peters, S., Hankin, S., Stone, V., 2010. A review of the in vivo and in vitro toxicity of silver and gold particulates: particle attributes and biological mechanisms responsible for the observed toxicity. Crit. Rev. Toxicol. 40 (4), 328-346.

Kolokassidou, C., Pashalidis, I., Costa, C., Efstathiou, A., Buckau, G., 2007. Thermal stability of solid and aqueous solutions of humic acid. Thermochim. Acta 454 (2), 78-83.

Lanphere, J.D., Rogers, B., Luth, C., Bolster, C.H., Walker, S.L., 2014. Stability and transport of graphene oxide nanoparticles in groundwater and surface water. Environ. Eng. Sci. 31 (7), 350-359.

Lecoanet, H.F., Wiesner, M.R., 2004. Velocity effects on fullerene and oxide nanoparticle deposition in porous media. Environ. Sci. Technol. 38 (16), 4377-4382.

Leenheer, J.A., Noyes, T., Werchaw, R.L., 1997. Acquisition and interpretation of liquidstate ${ }^{1} \mathrm{H}$ NMR spectra. Nuclear Magnetic Resonance Spectroscopy in Environmental Chemistry. 295

$\mathrm{Li}, \mathrm{K}$., Chen, Y., 2012. Effect of natural organic matter on the aggregation kinetics of $\mathrm{CeO}_{2}$ nanoparticles in $\mathrm{KCl}$ and $\mathrm{CaCl}_{2}$ solutions: measurements and modeling. J. Hazard. Mater. 209, 264-270.

Li, Z., Sahle-Demessie, E., Hassan, A.A., Sorial, G.A., 2011. Transport and deposition of $\mathrm{CeO}_{2}$ nanoparticles in water-saturated porous media. Water Res. 45 (15), 4409-4418.

Li, Z., Hassan, A.A., Sahle-Demessie, E., Sorial, G.A., 2013. Transport of nanoparticles with dispersant through biofilm coated drinking water sand filters. Water Res. 47 (17), 6457-6466.

Limbach, L.K., Li, Y., Grass, R.N., Brunner, T.J., Hintermann, M.A., Muller, M., Gunther, D., Stark, W.J., 2005. Oxide nanoparticle uptake in human lung fibroblasts: effects of particle size, agglomeration, and diffusion at low concentrations. Environ. Sci. Technol. 39 (23), 9370-9376

Lin, W., Huang, Y.-w., Zhou, X.-D., Ma, Y., 2006. Toxicity of cerium oxide nanoparticles in human lung cancer cells. Int. J. Toxicol. 25 (6), 451-457.

Lin, D., Liu, N., Yang, K., Xing, B., Wu, F., 2010. Different stabilities of multiwalled carbon nanotubes in fresh surface water samples. Environ. Pollut. 158 (5), 1270-1274.

Liu, X., Chen, G., Su, C., 2012. Influence of collector surface composition and water chemistry on the deposition of cerium dioxide nanoparticles: QCM-D and column experiment approaches. Environ. Sci. Technol. 46 (12), 6681-6688.

Lu, Y., Xu, X., Yang, K., Lin, D., 2013. The effects of surfactants and solution chemistry on the transport of multiwalled carbon nanotubes in quartz sand-packed columns. Environ. Pollut. 182, 269-277.

Luthy, R.G., Aiken, G.R., Brusseau, M.L., Cunningham, S.D., Gschwend, P.M., Pignatello, J.J., Reinhard, M., Traina, S.J., Weber, W.J., Westall, J.C., 1997. Sequestration of hydrophobic organic contaminants by geosorbents. Environ. Sci. Technol. 31 (12), 3341-3347.

Lv, X., Gao, B., Sun, Y., Shi, X., Xu, H., Wu, J., 2014. Effects of humic acid and solution chemistry on the retention and transport of cerium dioxide nanoparticles in saturated porous media. Water Air Soil Pollut. 225 (10), 2167.

Malcolm, R.L., 1989. Applications of solid-state ${ }^{13} \mathrm{C}$ NMR spectroscopy to geochemical studies of humic substances. Humic substances II. In search of structure 2, 339-372.

Mao, J., Hu, W., Schmidt-Rohr, K., Davies, G., Ghabbour, E., Xing, B., 2000. Quantitative characterization of humic substances by solid-state carbon-13 nuclear magnetic resonance. Soil Sci. Soc. Am. J. 64 (3), 873-884. 
Martin, T.D., 2003. Method 200.5 Determination of Trace Elements in Drinking Water by Axially Viewed Inductively Coupled Plasma-Atomic Emission Spectrometry. US Environmental Protection Agency, Cincinnati, Ohio, p. 45268.

Marzun, G., Streich, C., Jendrzej, S., Barcikowski, S., Wagener, P., 2014. Adsorption of colloidal platinum nanoparticles to supports: charge transfer and effects of electrostatic and steric interactions. Langmuir 30 (40), 11928-11936.

Masui, T., Yamamoto, M., Sakata, T., Mori, H., Adachi, G.-y., 2000. Synthesis of BN-coated $\mathrm{CeO}_{2}$ fine powder as a new UV blocking material. J. Mater Chem. 10 (2), 353-357.

Maurice, P.A., Pullin, M.J., Cabaniss, S.E., Zhou, Q., Namjesnik-Dejanovic, K., Aiken, G.R., 2002. A comparison of surface water natural organic matter in raw filtered water samples, XAD, and reverse osmosis isolates. Water Res. 36 (9), 2357-2371.

Maxfield, R., Mindak, B., 1985. EPA Method Study 27, Method 200.7: Trace Metals by ICP. US Environmental Protection Agency, Office of Research and Development, Environmental Monitoring and Support Laboratory.

McCurry, D.L., Speth, T.F., Pressman, J.G., 2011. Lyophilization and reconstitution of reverse-osmosis concentrated natural organic matter from a drinking water source. J. Environ. Eng. 138 (4), 402-410.

Montini, T., Melchionna, M., Monai, M., Fornasiero, P., 2016. Fundamentals and catalytic applications of $\mathrm{CeO}_{2}$-based materials. Chem. Rev. 116 (10), 5987-6041.

Mosley, L.M., Hunter, K.A., Ducker, W.A., 2003. Forces between colloid particles in natural waters. Environ. Sci. Technol. 37 (15), 3303-3308.

Mylon, S.E., Chen, K.L., Elimelech, M., 2004. Influence of natural organic matter and ionic composition on the kinetics and structure of hematite colloid aggregation: implications to iron depletion in estuaries. Langmuir 20 (21), 9000-9006.

Newman, R., Tate, K., 1991. ${ }^{13} \mathrm{C}$ NMR characterization of humic acids from soils of a development sequence. Eur. J. Soil Sci. 42 (1), 39-46.

Newman, R., Theng, B., Filip, Z., 1987. Carbon-13 nuclear magnetic resonance spectroscopic characterisation of humic substances from municipal refuse decomposing in a landfill. Sci. Total Environ. 65, 69-84.

Pelley, A.J., Tufenkji, N., 2008. Effect of particle size and natural organic matter on the migration of nano-and microscale latex particles in saturated porous media. J. Colloid Interface Sci. 321 (1), 74-83.

Petosa, A.R., Jaisi, D.P., Quevedo, I.R., Elimelech, M., Tufenkji, N., 2010. Aggregation and deposition of engineered nanomaterials in aquatic environments: role of physicochemical interactions. Environ. Sci. Technol. 44 (17), 6532-6549.

Petryshyn, R., Yaremko, Z., Soltys, M., 2010. Effects of surfactants and pH of medium on zeta potential and aggregation stability of titanium dioxide suspensions. Colloid 72 (4), 517-522.

Peuravuori, J., Paaso, N., Pihlaja, K., 1999. Kinetic study of the thermal degradation of lake aquatic humic matter by thermogravimetric analysis. Thermochim. Acta 325 (2), 181-193.

Pietro, M., Paola, C., 2004. Thermal analysis for the evaluation of the organic matter evolution during municipal solid waste aerobic composting process. Thermochim. Acta 413 (1), 209-214.

Potter, B.B., Wimsatt, J.C., 2012. USEPA method 415.3: quantifying TOC, DOC, and SUVA. J. Am. Water Works Assoc. 104 (6), E358-E369.

Pressman, J.G., Richardson, S.D., Speth, T.F., Miltner, R.J., Narotsky, M.G., Hunter, I., Sidney, E., Rice, G.E., Teuschler, L.K., McDonald, A., Parvez, S., 2010. Concentration, chlorination, and chemical analysis of drinking water for disinfection byproduct mixtures health effects research: US EPA's four lab study. Environ. Sci. Technol. 44 (19), 7184-7192.

Pressman, J.G., McCurry, D.L., Parvez, S., Rice, G.E., Teuschler, L.K., Miltner, R.J., Speth, T.F., 2012. Disinfection byproduct formation in reverse-osmosis concentrated and lyophilized natural organic matter from a drinking water source. Water Res. 46 (16), 5343-5354.

Quik, J.T., Lynch, I., Van Hoecke, K., Miermans, C.J., De Schamphelaere, K.A., Janssen, C.R., Dawson, K.A., Stuart, M.A.C., Van De Meent, D., 2010. Effect of natural organic matter on cerium dioxide nanoparticles settling in model fresh water. Chemosphere 81 (6), 711-715.

Rossman, P.D., 2014. Characterizing Variability in Ohio River NOM and Validating Reconstituted Freeze-Dried NOM as a Surrogate for its Aqueous Source. University of Cincinnati.

Ryan, J.N., Elimelech, M., 1996. Colloid mobilization and transport in groundwater. Colloids Surf A Physicochem Eng Asp 107, 1-56.

Sardessai, S., Wahidullah, S., 1998. Structural characteristics of marine sedimentary humic acids by CP/MAS ${ }^{13} \mathrm{C}$ NMR spectroscopy. Oceanol. Acta 21 (4), 543-550.

Seaton, A., Tran, L., Aitken, R., Donaldson, K., 2009. Nanoparticles, human health hazard and regulation. J. R. Soc. Interface rsif20090252.

Seo, D.K., Park, S.S., Kim, Y.T., Hwang, J., Yu, T.-U., 2011. Study of coal pyrolysis by thermogravimetric analysis (TGA) and concentration measurements of the evolved species. J. Anal. Appl. Pyrolysis 92 (1), 209-216.

Sharp, E.L., Parsons, S.A., Jefferson, B., 2006. Seasonal variations in natural organic matter and its impact on coagulation in water treatment. Sci. Total Environ. 363 (1), 183-194.

Shurygina, E., Larina, N., Chubarova, M.A., Kononova, M., 1971. Differential thermal analysis (DTA) and thermogravimetry (TG) of soil humus substances. Geoderma 6 (3), 169-177.

Thorn, K.A., Arterburn, J.B., Mikita, M.A., 1992. Nitrogen-15 and carbon-13 NMR investigation of hydroxylamine-derivatized humic substances. Environ. Sci. Technol. 26 (1), 107-116.

Tian, Y., Gao, B., Silvera-Batista, C., Ziegler, K.J., 2010. Transport of engineered nanoparticles in saturated porous media. J. Nanopart. Res. 12 (7), 2371-2380.

Tufenkji, N., Elimelech, M., 2004. Correlation equation for predicting single-collector efficiency in physicochemical filtration in saturated porous media. Environ. Sci. Technol. 38 (2), 529-536.

Wagner, S., Gondikas, A., Neubauer, E., Hofmann, T., von der Kammer, F., 2014. Spot the difference: engineered and natural nanoparticles in the environment-release, behavior, and fate. Angew. Chem. Int. Ed. 53 (46), 12398-12419.

Xing, B., Chen, Z., 1999. Spectroscopic evidence for condensed domains in soil organic matter. Soil Sci. 164 (1), 40-47.

Yang, K., Xing, B., 2009. Adsorption of fulvic acid by carbon nanotubes from water. Environ. Pollut. 157 (4), 1095-1100.

Yao, K.-M., Habibian, M.T., O'Melia, C.R., 1971. Water and waste water filtration. Concepts and applications. Environ. Sci. Technol. 5 (11), 1105-1112.

Young, K.D., LeBoeuf, E.J., 2000. Glass transition behavior in a peat humic acid and an aquatic fulvic acid. Environ. Sci. Technol. 34 (21), 4549-4553.

$\mathrm{Yu}, \mathrm{L}$., Xi, J., 2012. $\mathrm{CeO}_{2}$ nanoparticles improved Pt-based catalysts for direct alcohol fuel cells. Int. J. Hydrog. Energy 37 (21), 15938-15947.

Zeyons, O., Thill, A., Chauvat, F., Menguy, N., Cassier-Chauvat, C., Oréar, C., Daraspe, J. Auffan, M., Rose, J., Spalla, O., 2009. Direct and indirect $\mathrm{CeO}_{2}$ nanoparticles toxicity for Escherichia coli and Synechocystis. Nanotoxicology 3 (4), 284-295.

Zhang, Y., Chen, Y., Westerhoff, P., Crittenden, J., 2009. Impact of natural organic matter and divalent cations on the stability of aqueous nanoparticles. Water Res. 43 (17), 4249-4257. 